\title{
UM NOVO MODELO SUSTENTÁVEL DE REUTILIZAÇÃO DE CONTAINERS INDUSTRIAIS EM SISTEMAS DE ALUGUEL DE BICICLETAS
}

\author{
Felipe Oliveira Arruda (UFPE); Amilton José Vieira de Arruda, Ph.D. \\ (UFPE); Manoel Guedes Alcoforado Neto (UFPE); \\ Paulo Roberto Silva, MSc . (UFPE)
} PALAVRAS CHAVE
Bikeshare; Containers reutilizados; Mobilidade urbana; Interatividade \& Sustentabilidade.

KEY WORDS

Bikeshare; Containers reused; Urban Mobility; Interactivity \& Sustainability.

\begin{abstract}
RESUMO
O projeto Container Bike consiste no desenvolvimento de um conceito que contempla a bicicleta como alternativa de transporte para a mobilidade urbana, por meio de um sistema simples e acessível de aluguel de bicicletas, adequado às características locais de várias cidades brasileiras. Os containers industriais, cada vez mais contemplados na arquitetura e no design por sua versatilidade e praticidade, são encontrados em cidades portuárias do mundo inteiro, utilizados como transporte de carga, tornando-se, porém, obsoletos após um curto período de tempo. Neste projeto, estas importantes caixas metálicas surgem com novas funções: seja como pontos exclusivos de BikeShare (aluguel de bicicletas) espalhados pela cidade e integrados à rede de transporte urbano, seja como ambientes confortáveis de lazer e interação, projetados e combinados para receber usuários e interessados em bicicletas. É importante perceber que hoje, e cada vez mais no mundo e no Brasil o conceito de mobilidade urbana se agrega ao conceito de qualidade de vida e com ele, o design que pode muitas vezes transformar esta realidade em algo prazeroso e ao mesmo tempo rentável.
\end{abstract}

\begin{abstract}
The Container bike project consists in developing a concept that covers the bicycle as transportation alternative for urban mobility, through a simple and accessible system of bike rentals, to meet local needs in several Brazilian cities. Industrial containers, increasingly addressed in architecture and design for its versatility and practicality, are found in port cities around the world, used as cargo transport, making it, but obsolete after a short period of time. In this project, these important metal boxes come with new functions: be as unique points of Bikeshare (bike rental) around the city and the integrated urban transport network, as is comfortable environments for recreation and interaction, designed and matched to users and receiving interested in bikes. It is important to realize that today, and increasingly in the world and in Brazil the concept of urban mobility is added to the concept of quality of life and with it, the design that can often turn this into something pleasurable and profitable at the same time.
\end{abstract}




\section{INTRODUÇÃO}

Écada vez mais urgente a necessidade de um sistema alternativo para a mobilidade urbana. De baixo custo operacional e não poluente para as cidades brasileiras. O problema ambiental gerado pela emissão de gases na atmosfera, decorrente da crescente quantidade de veículos movidos a derivados de petróleo, somado à superlotação das vias publicas, ocupadas preponderantemente por automóveis, só reforçam tal necessidade.

O uso da bicicleta como serviço público de transporte já é uma realidade em inúmeras cidades européias, como Paris, Amsterdã e Berlim, permitindo não só a integração entre as pessoas de maneira responsável, cidadã e colaborativa, como também favorecendo um instrumento de lazer e bem estar para a população.

Partindo-se do pressuposto de que os atuais sistemas de mobilidade de grandes cidades do mundo tendem à saturação devido ao grande incentivo ao transporte individual, em detrimento ao transporte coletivo, observa-se a movimentação coletiva para criação de alternativas sustentáveis baseadas nos mais diversos tipos de produtos e serviços.

Segundo John Thackara, o "design de serviços acontece com intuito de organizar as coisas para que as pessoas que necessitam fazer algo, estejam conectadas a outras pessoas e equipamentos." (Thackara, 2006, p.19).

Seguindo este conceito, nem sempre o usuário terá a posse sobre os objetos utilizados para utilizá-los: por meio da colaboração entre seres inseridos em um mesmo contexto, com as mesmas aspirações e desejos, deverão ser criados meios para compartilhar estes produtos, sem sacrificar os benefícios dos mesmos.

Por que temos que possuir tudo que precisamos? Não seria menos pesado para o ambiente e para a pessoa em si se ela pudesse usar o objeto que precisa, quando precisa, onde precisa, sem ter de carregá-lo para todo o lugar? (Thackara, 2006, p.18)

Tomando como foco a mobilidade urbana, compreendida como um conjunto de fatores que permitem o deslocamento de pessoas dentro do espaço urbano, este compartilhamento pode se traduzir no conceito de intermodalidade (Thackara, 2006), que, segundo o autor, permite utilizar meios de transportes diferentes em trechos diferentes, criando meios acessíveis para que mais pessoas se desloquem dentro de um mesmo espaço, para um mesmo local, ao mesmo tempo, sem denegrir ou dificultar o acesso de outras pessoas. Segundo a definição da Política Nacional da Mobilidade Urbana Sustentável, desenvolvida pelo
Ministério das Cidades (BRASIL, 2004), a mobilidade urbana está associada às pessoas e aos bens que se relacionam com as necessidades de deslocamentos no espaço urbano, de acordo com as atividades nele desenvolvidas:

Na geografia urbana, o deslocamento nas cidades é
analisado e interpretado em termos de um esquema
conceitual que articula a mobilidade urbana que são:
as massas populacionais e seus movimentos; a rede,
representada pela infra-estrutura que canaliza os
deslocamentos no espaço e no tempo; e os fluxos, que
são as macro decisões ou condicionantes que orientam
o processo no espaço. (Raia Jr, 2000)

Desta maneira, visando a aplicação de um sistema que atenda aos conceitos de mobilidade, sustentabilidade, compartilhamento e integração, deve-se pensar no contexto para o qual se está propondo uma mudança, pois o envolvimento das pessoas em um novo sistema de mobilidade depende não só da cultura sob a qual elas estão imersas, mas também dos estímulos que recebem e que as fazem refletir sobre seu próprio meio. Esta idéia passa necessariamente por diversos níveis da sociedade, podendo partir seja de políticas publicas que foquem na melhoria da qualidade de vida das pessoas e do meio ambiente, como também partindo de setores mais focados no desenvolvimento da cidade.

$O$ autor Ezio Manzini defende a idéia de que é mais fácil mudar hoje alguns modos de fazer as atividades e políticas do que precisar de grandes passos no futuro. É interessante observar, por exemplo, como em um determinado período, fenômenos paralelos mudam constantemente os sistemas existentes orientados localmente, exigindo cada vez mais posturas e pensamentos novos para enfrentar os desafios do futuro. Dentre os principais critérios para gerar soluções sustentáveis, o autor define que devem ser combinados os princípios éticos, o uso de materiais e energia de baixa intensidade e o alto potencial regenerativo do sistema proposto (MANZINI; JEGOU; 2003). O design estratégico se apresenta, justamente, como importante catalisador na tentativa de atingir as mudanças necessárias, favorecendo resultados em larga escala aliando conceitos e práticas essenciais para transformar uma idéia em realidade.

\section{MOBILIDADE URBANA SUSTENTÁVEL}

Estudos na área de mobilidade e planejamento urbano apontam que a primeira classificação dos transportes se dá pela sua esfera de atuação: pública ou privada. A primeira está à disposiç̧ão do público mediante pagamento e sempre está submetido a algum tipo de controle go- 
vernamental. A segunda é utilizada apenas pelo proprietário ou por quem ele permita e está submetido a regras gerais do código de transito. Ambos os meios podem ser comparados levando em consideração suas variadas características: por exemplo, a quantidade de pessoas que cabem dentro do veículo (capacidade física) ou o número de pessoas que podem ser transportadas por vários veículos em uma hora, em determinada via (capacidade dinâmica) (VASCONCELLOS, ibid., p. 58).

É notável que a motocicleta e a bicicleta são os veículos com menor capacidade física, já que comportam uma ou duas pessoas, no máximo. O próximo veículo é o automóvel, que comporta 5 a 9 passageiros (a depender do modelo), seguido pelos micro-ônibus, pelos ônibus comuns e ônibus articulados (dois corpos), chegando aos veículos metro-ferroviários, comportando até 1.500 pessoas no total (somando a capacidade de vários vagões).

Estes dados não demonstram, porém, que apesar do carro ter a capacidade de transportar de 5 a 9 passageiros, suas dimensões médias são consideravelmente menores do que os demais veículos, demonstrando como são extremamente ineficientes do ponto de vista da otimização do espaço urbano. Ou seja, 4 carros enfileirados levam aproximadamente 8 pessoas ocupando o mesmo espaço físico de um ônibus que leva 80 pessoas.

Faz-se, portanto, de extrema necessidade o desenvolvimento de estratégias para a criação de novas formas de transito e transporte em contraposição ao incremento do transporte individual e as facilidades que surgem com ele. $\mathrm{E}$, é ainda, mais necessário dar as pessoas à chance de escolher formas mais eficientes para se deslocar sem que dependam tão fortemente do uso do veículo individual. Entretanto é impossível pensar em mobilidade urbana sem pensar nas ruas, calçadas e ciclovias, já que são por elas que as pessoas fazem à maioria dos seus deslocamentos.

O conceito de Desenvolvimento Sustentável surgiu pela primeira vez nos anos 80 , e atualmente vem tomando cada vez mais espaço nas discussões políticas, econômicas e sociais do planeta. Ao longo do tempo, várias definições tomaram corpo, porém sempre tendo em vista dois objetivos: o desenvolvimento econômico e a conservação ambiental.

O Desenvolvimento Sustentável sugere, de fato, qualidade em vez de quantidade, com a redução do uso de matérias-primas e produtos e o aumento da reutilização e da reciclagem. (WWF-BRASIL, 2005).

As cidades crescem, em geral, de forma acelerada, espontânea e de modo não planejado. Com isso passam a conviver com uma série de problemas, dentre eles a falta de infra-estrutura urbana, sobretudo para a população de menor renda, e a degradação ambiental. A forma de ocupação do solo urbano, associada à políticas setoriais pouco integradas, acaba por influenciar negativamente o sistema de mobilidade das cidades (MINISTÉRIO DAS CIDADES, 2005).

De acordo com o que foi apresentado, porém, a situação em diversas cidades brasileiras não é o que podese chamar de sustentável e muitas vezes o conceito de Mobilidade Urbana é deixado de lado, quando na verdade deveria ser um termo indispensável na visão econômica e social. Este conceito, atualmente, é a chave para oferecer acesso aos empregos, comércio, serviço, habitação, educação, cultura e lazer, permitindo a qualidade de vida dos seres que usufruem da cidade.

\subsection{Bicicletas como Alternativa para o Caos Urbano}

As bicicletas se mostram como solução de grande eficiência para o tráfego local, principalmente em grandes cidades e em um raio de pequena distancia. Estudos mostram, por exemplo, a bicicleta como um dos mais rápidos veículos em percurso de até $4 \mathrm{~km}$, apresentando o menor consumo de energia primária por passageiro$\mathrm{km}$. Seus benefícios, portanto, são consideráveis tanto para a comunidade urbana quanto para seus usuários, pois envolvem também aspectos de bem-estar pessoal, saúde e locomoção.

Dentre as alternativas viáveis, a integração do transporte por bicicletas a ônibus e metrô e sistemas de aluguel ou empréstimos em pontos de integração modal oferecem uma ótima solução para a distribuição local de usuários de transportes de massa. Estes sistemas integrados já se encontram em uso em diversas cidades pelo mundo, desde pequenas províncias na Europa até megalópoles na China.

No Brasil, de acordo com o relatório comparativo 2003/2007 da mobilidade urbana da ANTP - Associação Nacional de Transportes Públicos, no período entre 2006 e 2007, as viagens por transporte coletivo apresentaram significativo crescimento, em especial o modo metroferroviário. As viagens de bicicleta vêm crescendo desde 2003, e teve um acréscimo de $8 \%$ de 2006 para 2007

Além disto, estudos enfatizam também o impacto econômico positivo da crescente adoção da bicicleta como meio de transporte, principalmente em economias em desenvolvimento, como é o caso do Brasil. Mesmo que 
os custos sociais do uso do automóvel ainda não sejam totalmente bancados pelo seu proprietário, o custo total é elevado e grande parte destes recursos é enviada para fora da economia local. Observa-se, desta maneira, que a troca do carro pela bicicleta, ao invés de ser um desestimulo à economia, liberaria partes destes recursos para serem usados em outros gastos, provavelmente estimulando a economia local em outros níveis de investimentos.

Nos últimos anos, com a implementação de políticas ambientais, alguns países estão investindo nas políticas sustentáveis de transportes, promovendo alterações modais para o ciclismo. Essas alterações vêm sendo defendidas no âmbito do desenvolvimento sustentável e da saúde das pessoas segundo Mariana Silveira, autora da dissertação de mestrado "Mobilidade sustentável: a bicicleta como um meio de transporte integrado" (RIO DE JANEIRO, 2010),

Outro importante fator que torna a bicicleta o centro das atenções é a diminuição da necessidade de espaço urbano para vagas de automóveis, o que gera uma importante economia com terrenos e construção destinado somente à estacionamentos, permitindo que estes recursos possam ser reinvestidos para solucionar outros problemas da cidade.

Segundo a Abraciclo - Associação brasileira dos fabricantes de motocicletas, ciclomotores, motonetas, bicicletas e similares, o mercado mundial de bicicletas no ano de 2007 teve um consumo de 122,5 milhões de bicicletas.

\subsection{A Bicicleta no Brasil}

O Brasil, com uma frota estimada em 60 milhões de bicicletas, ocupa posição expressiva no mundo quanto à venda deste veículo. No entanto, conta com cerca de $2.505 \mathrm{~km}$ de infra-estrutura exclusiva à circulação da bicicleta, pouca com relação à sua dimensão continental (MINISTÉRIO DAS CIDADES, 2007). A bicicleta é considerada o veículo individual mais utilizado nos pequenos centros urbanos (cidades com menos de 50 mil habitantes), que representam mais de $90 \%$ do total das cidades brasileiras. Nas cidades médias, o que muda em relação às pequenas cidades é a presença eventual de linhas de transporte coletivo, às vezes em condições precárias, pois a exploração dos serviços só se torna viável quando a demanda é concentrada e as distâncias são grandes. (SILVEIRA, Mariana. 2010).

Dados mostram, por exemplo, que entre os usuários mais freqüentes da bicicleta encontram-se industri- ários, comerciários, operários da construção civil, estudantes, entregadores de mercadorias, carteiros e outras categorias de trabalhadores. Os períodos mais favoráveis à constatação desse evento são: entre $6 \mathrm{~h}$ e $7 \mathrm{~h}$, e das $16 \mathrm{~h}$ às $19 \mathrm{~h}$ dos dias úteis.

Atualmente, porém, podem ser encontrados diversos movimentos sociais e empreendedores que elevam o status da bicicleta e realmente fazem com que o entorno urbano seja modificado. Pesquisa realizada pelo Instituto Maurício de Nassau com o cidadão recifense, por exemplo, sinaliza um sentimento novo, ainda não claramente percebido nas ruas e certamente ignorado pelo gestores municipais. O dado é revelador: $93 \%$ dos entrevistados afirmaram ser favoráveis à construção de ciclovias na capital.

Outro exemplo encontrado no Brasil, na cidade do Rio de Janeiro, o Sistema Samba (Solução Alternativa para Mobilidade por Bicicletas de Aluguel), implantado em 2008, oferece uma solução tecnológica sustentável para a disponibilização e gerenciamento de bicicletas de aluguel como meio de pequeno percurso.

\subsection{Intermodalidade como Alternativa}

Sistemas de Bikeshare, ou compartilhamento de bicicletas, removem certas barreiras relacionadas à propriedade de bicicletas, incluindo preocupação com roubo, falta de estacionamento em centros urbanos ou até mesmo questões de armazenamento e manutenção. Estes sistemas estão se tornando cada vez mais comuns em diversas cidades do mundo.

O maior deles está localizado em Hangzhou, na China, onde mais de 240 mil viagens são realizadas diariamente nas 50 mil bicicletas públicas de aluguel, com planos de expansão para 175 mil bicicletas até 2020.

Canadá é outro país que demonstra interesse nessa tendência mundial: além de possuir um eficiente sistema público de aluguel de bicicletas em diversas cidades, o país investe constantemente na renovação de seu sistema de transporte, enfatizando a melhoria em ciclovias, construção de estacionamentos e melhorando a integração com outros meios de transporte.

É neste contexto que encontramos o conceito de integração intermodal, definida pelo uso de dois ou mais meios de transportes diferenciados no mesmo deslocamento. A intermodalidade entre a bicicleta e o transporte público é caracterizada pelo deslocamento onde um trecho é percorrido em bicicleta e outro no transporte público, e é feita através de duas formas (AQUINO e ANDRADE, 2007): 
1. Transporte da bicicleta nos veículos de transporte público (trens, VLTs, ônibus, metrôs, barcas, entre outros);

2. Estacionamentos para bicicletas em áreas dentro ou perto das estações (ou paradas, no caso de ônibus) de transportes públicos.

Pode ser dito, porém, que a integração entre a bicicleta e outros meios de transportes públicos constitui grande desafio do transporte urbano moderno. E aproximar a bicicleta dos terminais e locais de grande demanda de passageiros é permitir a valorização dos meios coletivos e a ampliação do raio de ação dos ciclistas nas cidades e nos espaços regionais (MINISTÉRIO DAS CIDADES, 2007).

As principais iniciativas para promover a integração da bicicleta com outros meios de transportes são:

a.Proporcionar rotas cicláveis até os pontos de paradas do transporte público; Oferecer pontos de transferência de boa qualidade, com bicicletários ou paraciclos;

b.Disponibilizar sistemas de aluguel de bicicletas, devidamente integrados e organizados;

c. Oferecer estacionamentos com segurança para as bicicletas; entre outros.

De acordo com o Ministério das Cidades (2007), bicicletários são caracterizados como estacionamentos de longa duração, com grande número de vagas, com controle de acesso e podem ser públicos ou privados.

Já os paraciclos são caracterizados como estacionamentos de curta ou média duração (até $2 \mathrm{~h}$, em qualquer período do dia), número de até 25 vagas (correspondente à área de duas vagas de veículos automotores), de uso público e sem qualquer controle de acesso, externos e sem zeladoria (SILVEIRA, Mariana. 2010).

Existem duas maneiras de se fazer esta integração: uma com a possibilidade de levar a bicicleta no ônibus, normalmente em compartimento ou rack na dianteira do veículo, e outra, a possibilidade de estacionar a bicicleta em paraciclo ou bicicletário próximo à parada de ônibus ou à estação de BRT.

\subsection{Adaptações de Containers para a Arquitetura}

As adaptações de um container para a arquitetura incluem o tratamento de isolamento, incorporando meIhorias térmicas e acústicas, o corte para portas e janelas para garantir uma iluminação adequada do espaço interior e os revestimentos internos, que incluem o piso e as paredes. Estas intervenções aparentemente parecem exigir elevados investimentos financeiros, porém deve-se considerar que o preço deste material, chega a ser bastante reduzido, garantindo uma estrutura mais barata do que em uma construção padrão de alvenaria, sem mencionar a economia com mão de obra.

Segundo Jure Kotnik, autor do livro "Container Architecture. This book contains 6441 containers":

\begin{abstract}
Ao mesmo tempo em que as pessoas se tornam mais conscientes com relação ao meio ambiente, várias vantagens ressaltam o uso de containers reutilizados, principalmente o fato de que eles são largamente recicláveis e reutilizáveis. De fato, se edifícios fossem totalmente construídos a partir de containers, o uso dos materiais para construção poderiam ser reduzidos sensivelmente. (...) A arquitetura de containers contempla plenamente o conceito projetual 3Rs: Reuse, Recicle e Reduza.
\end{abstract}

Outro importante fator trata da adaptação de containers para o solo, já que para obter uma área construída, não seria mais necessário intervir maciçamente no terreno e no seu entorno, poupando custos financeiros e ambientais, assim como o tempo de construção, a poluição que tudo isto envolve, a geração de resíduos e desperdícios de materiais no canteiro de obras. Uma pequena construção de containers, por exemplo, pode ser perfeitamente erguida em um dia, enquanto a criação de largas estruturas para obter a mesma área construída pode necessitar de várias semanas para ser implantada.

\section{CONCEITUAÇÃO E DEFINIÇÃO DO PROJETO}

Decorrente da pesquisa com foco na mobilidade urbana e no uso da bicicleta como alternativa de meio de transporte sustentável, assim como também da análise da necessidade de um sistema acessível, com fortes características locais, foram desenvolvidos os seguintes conceitos que definiram o projeto:

1. Criação de sistema de transporte alternativo focado na bicicleta e incorporando um serviço de locação integrado a outros meios de transporte na cidade do Recife;

2. Estimulo à ocupação do espaço publico urbano de forma consciente e não poluidora, por meio de ações que promovam o bem estar da população e da mobilidade urbana sustentável;

3. Uso de containers reutilizados, projetados e transformados para abrigar as bicicletas de aluguel, além de oferecer uma opção de lazer e descanso para os usuários, fomentando o uso da bicicleta como meio de transporte sustentável;

4. Apresentação e composição dos Containers: 
a. Módulos independentes, nos quais o serviço de aluguel de bicicletas é disponibilizado, integrados aos principais pontos de transporte da cidade (ônibus, BRT e metrôs). São de extrema objetividade, já que constituem uma única unidade de container, contendo 24 bicicletas cada. Estas são dispostas verticalmente, de maneira simples, permitindo o fácil manuseio. Estes módulos exigem pouco espaço e mão de obra mínima para instalação e estão localizados em pontos estratégicos da cidade, com acesso à ciclovias e ciclofaixas, conforme figura 1.

Figura 1 - Desenho do Modulo Independente

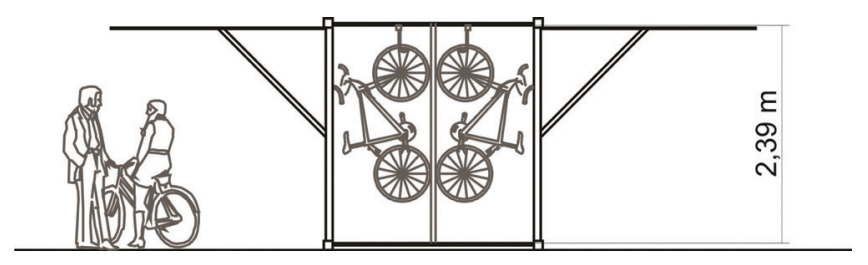

Fonte: Elaborado pelos autores com base no projeto realizado.

b. Ambientes integrados, no qual os containers são combinados para oferecer um equipamento de lazer e descanso para usuários e interessados na bicicleta, além do serviço de aluguel citado anteriormente. Neste ambiente é possível realizar o cadastro no sistema e também aproveitar o serviço no Lounge, localizado no andar superior. Exige maior espaço para instalação e montagem, sendo ideal sua utilização em parques e praças, devidamente integradas à ciclovias e ciclofaixas da cidade e também a outros meios de transporte. Ver figura 2.

Figura 2. Modelo Virtual da proposta de Ambientes Integrados

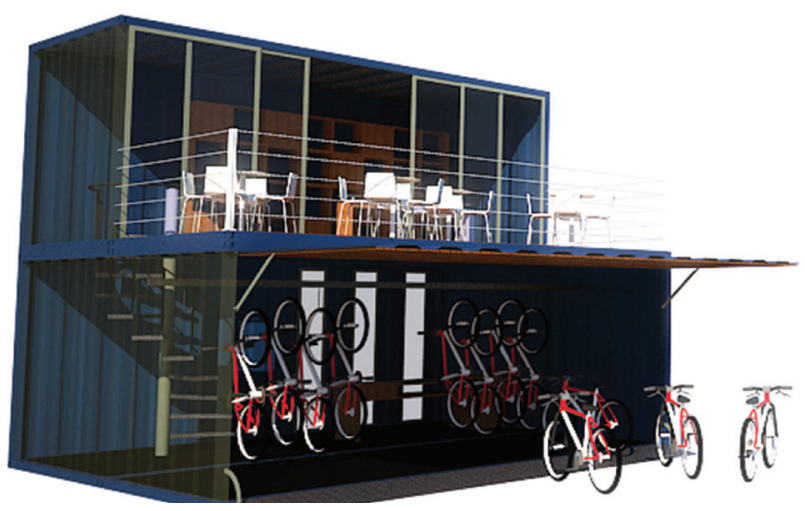

Fonte: Elaborado pelos autores com base no projeto realizado.
Analisando o entorno urbano da Cidade do Recife, localizada no litoral do Estado de Pernambuco, observaram-se características importantes que favoreceram a contextualização do Container Bike nesta cidade. Talvez a mais importante delas é justamente a de ser uma cidade em grande parte integrante de um vasto ecossistemas que acaba esculpindo a cidade de forma particular: cortada por rios, limitada geograficamente por morros e matas, a cidade parece necessitar de uma nova forma de respirar, algo que traga um movimento diferente e favoreça seus moradores.

O objetivo foi integrar os diversos pontos do Container Bike no centro da cidade, não por acaso uma das áreas que mais sofrem com o caos intenso de veículos motorizados. Esta área, composta por ilhas interligada por belas pontes, foi a escolhida para, de certa forma, dar vida a este projeto.

Os pontos escolhidos com análise técnica, identifica os cruzamentos e os parques que abrigam o projeto para melhor servir à população através de grandes praças corredores viários, alguns poucos unidos por ciclovias e ciclofaixas, que servem de abrigo para o Container Bike. Ver figura 3

Figura 3. Modelo Virtual do Projeto Container Bike

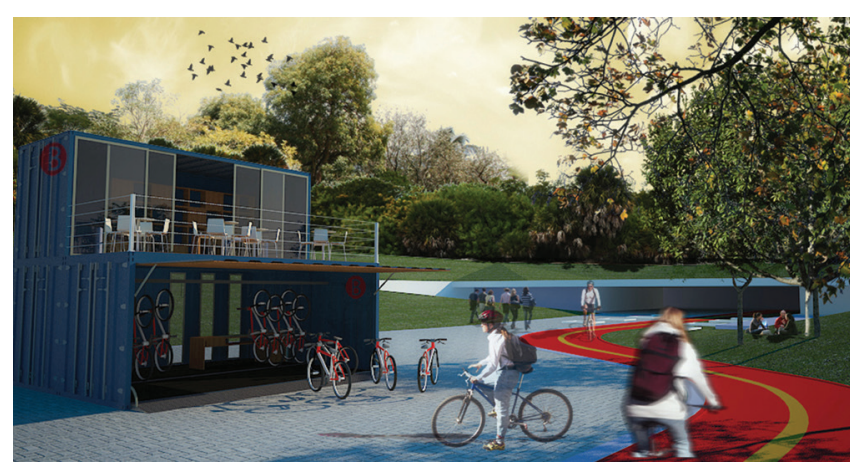

Fonte: Elaborado pelos autores com base no projeto realizado.

\section{CONCLUSÃO}

O projeto Container Bike visa contribuir de maneira significativa em diversos aspectos da vida coletiva nas grandes cidades brasileiras. Primeiramente, este projeto conceitual se apropria da ideia de sistemas de aluguel de bicicletas, ou bike sharing, já largamente aplicado em cidades do mundo inteiro, algumas delas brasileiras. $\mathrm{O}$ objetivo é, justamente, despertar e fomentar a necessidade e o interesse da população para um meio de transporte que cada vez mais se destaca por sua eficiência e por suas implicações positivas para com a cidade e pessoas. 
Sobretudo ainda disponibilizado para a população por meio de sistemas integrados de aluguel e compartiIhamento, facilitando o acesso às bicicletas. Por outro ladro, o conceito de containers reutilizados para a arquitetura, propiciando menos impacto ao meio ambiente e ao mesmo tempo permitindo baixos custos operacionais e de manutenção da estrutura, visando criar novos ambientes sociais em uma cidade já saturada, como o Recife.

Estas estruturas industriais, flexíveis e modulares, devidamente planejadas, são dispostas pela cidade de modo a facilitar o acesso das bicicletas por parte da população, ao mesmo tempo tornando-se marcos, ou pontos de encontro dos ciclistas.

Fica claro, por fim, que o projeto se adequa perfeitamente ao contexto econômico e social da cidade, com o incentivo e atuação cada vez maior das bicicletas como alternativa de transporte para o trabalho e lazer da população.

\section{REFERÊNCIAS}

1. AQUINO, A. P. P., ANDRADE, N. P. A integração entre trem e bicicleta como elemento de desenvolvimento urbano sustentável, $3^{\circ}$ Concurso de Monografia CBTU - A cidade nos trilhos. 2007

2. BICI CWB. Plano de Mobilidade - Infra-estrutura Cicloviária, Curitiba. 2008.

3. COMISSÃO EUROPÉIA, 2000, Cidades para Bicicletas, Cidades de Futuro, Luxemburgo, Serviços das Publicações Oficiais das Comunidades Européias. 2008.

4. EMTU - Recife. Empresa Metropolitana de Transportes Urbanos, Pesquisa Domicilar 1997, Região Metropolitana do Recife. Recife. 1998.

5. KOTNIK, Jure. Container Architecture - This book contains 6441 containers. 2008.

6. MINISTÉRIO DAS CIDADES. Mobilidade urbana é desenvolvimento Urbano. Brasília: 2005.

7. MINISTÉRIO DAS CIDADES. PlanMob - Construindo a cidade sustentável:

8. Caderno de referências para a elaboração de plano de mobilidade sustentável. Brasília: 2007.

9. MINISTÉRIO DAS CIDADES. Plano de Mobilidade por
Bicicleta nas Cidades, Coleção Bicicleta Brasil, caderno 1, Secretaria Nacional de Transporte e da Mobilidade Urbana, Brasília: 2007.

10. GOVERNO DO ESTADO DE PERNAMBUCO. Estratégia de desenvolvimento da Região Metropolitana do Recife - 2003/2015, Metrópole Estratégica, Versão Técnica. 2002

11. VASCONCELLOS, Eduardo Alcântara de. A cidade, o transporte e o trânsito. São Paulo: Pró Livros, 2005. 